\title{
Comparison of Clinical and Angiographic Profiles of Patients with or without Left Main Coronary Artery Disease
}

\author{
SUMAN KUMAR BISWAS, MANZOOR MAHMOOD, NAVEEN SHEIKH, MD. FAKHRUL ISLAM KHALED, \\ AHMED SAIFUL BARI, ABU SADIQUE ABDULLAH, RASHEDUL ISLAM, SANJIDA ANSARI, \\ MOHAMMAD SAFIUDDIN
}

Department of Cardiology, University Cardiac,Center, Bangabandhu Sheikh Mujib Medical University (BSMMU), Shahbag, Dhaka, Bangladesh Address of Correspondence: Dr. Suman Kumar Biswas, Resident, Department of Cardiology, University Cardiac Center, BSMMU, Dhaka,

Bangladesh, E-mail: suman.kumar.ssmc@gmail.com

\begin{abstract}
Background: Left main coronary artery disease constitutes highest risk lesion subset of CAD population. Flow dynamics and pathophysiology in the left main coronary artery are different from that of the other coronary arteries. So traditional risk factors might interact differently with left main artery resulting in different clinical and angiographic characteristics compared to others. Anatomic pattern evaluation in left main coronary artery disease is important in deciding best management options. However, their pattern and profiles were variably shown in different studies with discrepant results suggesting geographic variation and lead to evaluation of characteristics in our own population. Better understanding this specific problem might lead to further improvement in its management.
\end{abstract}

Methods: It was an observational cross-sectional study. Ninety-one adult coronary artery disease patients over the period of one year who underwent invasive coronary angiogram were studied. Study subjects were divided into two groups after coronary angiogram: Left main (Group 1) and Non-left main (Group 2) CAD. Demographic data, risk factor profiles and angiographic patterns of both groups were compared to see if any statistically significant difference present or not.

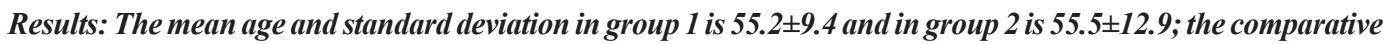
analysis showed no statistically significant difference. Most of the patients were male 69 (76\%) and the comparative study showed statistically significant differences $(p=0.046)$ which showed left main disease tended to be higher in male. Majority (64\%) had BMI in normal range with no significant difference. Among the risk factors comparison, diabetes and family history of CAD showed significant association with the left main cohort ( $<<0.05)$. Non-ST elevated ACS was the most common presentation and significantly associated with the left main group $(p<0.05)$. On coronary angiogram, there were 80 patients $(87.92 \%)$ who had no left main artery involvement while 11 patients (12.08\%) had left main disease. The comparative study of coronary artery involvement among the two groups reveals no statistically significant differences $(p>0.05)$ but triple vessel disease was found more commonly than single and double vessel disease. Distal lesions (64\%) were found more frequently than other types of left main stenosis followed by ostio-proximal lesion (36\%).

Conclusion: In the patients with left main coronary artery disease, male gender, diabetes mellitus, positive family history and presentation with non-ST elevation ACS were found to be significantly associated. Distal left main lesion and triple vessel disease were commonly found.

Keywords: Left main coronary artery disease; LMCA; Coronary angiography; Risk factors, Coronary artery disease, $C A D$

University Heart Journal 2022; 18(1): 3-9

Introduction

Left main coronary artery (LMCA) disease portends higher prognostic risk as a result of the large myocardial territory at risk, ranging from $75 \%$ to $100 \%$, depending on the dominance of the left coronary circulation. ${ }^{1}$ Among obstructive coronary artery diseases (CAD), significant left main coronary artery (LMCA) disease is the highestrisk lesion subset and is associated with poorer clinical outcomes compared with non- LMCA disease. ${ }^{2}$ The spectrum of clinical presentation of LMCA varies from asymptomatic to sudden death. ${ }^{3}$ Diagnosis and management of significant LMCA disease is a source of 
clinical apprehension and uncertainty which is not uncommonly found in patients undergoing coronary angiography. ${ }^{1}$ The anatomic extent and complexity of $\mathrm{CAD}$ are major factors in deciding the best management approach of LMCA disease. ${ }^{4}$ Over the last 2 decades, patient risk profiles and treatment strategy of LMCA disease have evolved remarkably over time. But, how the characteristics, treatment, and clinical outcomes of patients with LMCA disease have evolved over time has not yet been fully evaluated. ${ }^{2}$ Diagnosis, evaluation and management of it pose numerous challenges and associated with increased mortality and morbidity unless early intervention is done. So, more attention should be paid on this population of CAD patients. Although several studies have been conducted in different parts of the world, there might be geographical variation in characteristics of LMCA disease and there is lack of data about these patients in Bangladesh. This observational study was conducted to know the clinical and angiographic profiles of patients with LMCA disease and its comparison with the non-left main counterpart to see if any difference was present or not that might help identify patients at risk and warrant intensification of management as better understanding of this specific problem can help in better management of patients.

\section{Methods}

Study design and Patients

This observational cross-sectional study was conducted at the Department of Cardiology, Bangabandhu Sheikh Mujib Medical University, Dhaka. The center has consistently been ranked as the one of the top hospitals in Bangladesh. Total duration was twelve months from January, 2020 to December, 2020. We studied 91 adult patients (age $\geq 18$ years) of coronary artery disease. Patients were excluded if they had cardiomyopathies, valvular heart disease, severe renal dysfunction, history of percutaneous coronary intervention and coronary artery bypass grafting. The protocol was approved by the local ethics committee and Institutional Review Board (IRB). Written informed consent was obtained from each patient after careful explanation.

\section{Study procedure}

Adult coronary artery disease patients who underwent invasive coronary angiography during the index period of hospitalization were included in this study as per inclusion and exclusion criteria. Detailed history, physical examination and relevant laboratory tests including ECG and echocardiogram were done. Then patients underwent invasive evaluation by coronary angiography performed via either the transfemoral or transradial approach by expert interventional cardiologist using standard protocols. Angiographic data were retrieved. Thereafter, all the patients who underwent coronary angiography were divided into two groups: those with significant LMCA stenosis (Group 1) and those with not i,e non-LMCA (Group 2). Then the two groups were compared to find out any statistically significant difference. A lesion was considered to be angiographically significant when $\geq 50 \%$ stenosis of the diameter of vessel lumen was compromised on at least 2 different views in the case of LMCA and $\geq 70 \%$ stenosis for the remaining coronary arteries, using as a reference the adjacent segment of the vessel without angiographic lesions. ${ }^{5}$

\section{Statistical analysis}

Keeping the research topic in concern, a preset easily understandable data sheet was used for data collection. After collection of all information, these data were checked, verified for consistency and edited for finalized result. Continuous variables are expressed as mean value \pm standard deviation or as median. Categorical variables are expressed as absolute number and percentages which were presented as frequency tables and charts. Continuous data were analyzed and compared by Student's t-test and categorical data by Chi-square test. Differences were considered significant when $P$ value less than 0.05 . Statistical analyses were carried out by SPSS version 25.0 windows software.

\section{Results \\ Demographics}

The age of the patients ranged from 33 to 79 years with mean age and standard deviation of 55.2 \pm 9.8 . The mean age with standard deviation in group 1 (LMCA) was $55.2 \pm 9.4$ and in group 2 (Non- LMCA) was 55.5 \pm 12.9 . Majority (68.1\%) of patients belonged to age group 4060 years. The comparative study of age between the two groups showed no statistically significant differences $(p>0.05)$. There were 69 (75.8\%) males and $22(24.2 \%)$ females in total. Among the males, 11 were in group 1 (LMCA) and 58 in group 2 (No LMCA). Among the females, all were in group 2 . The comparative study among the two groups showed statistically significant differences $(p=0.046)$ which shows left main disease tends to be higher in male. The comparative analysis of body mass index (BMI) among the two groups showed no statistically significant difference $(\mathrm{p}>0.05)$. 


\section{Clinical presentations}

Majority (45\%) of the study population presented with non-ST elevated-acute coronary syndrome (NSTE-ACS). Of them, $73 \%$ was in group 1 vs. $41 \%$ in group 2 . The comparative study of the clinical presentations among the group 1 (LMCA) and the group 2 (No LMCA) shows statistically significant difference between the two groups in respect to NSTE-ACS ( $p=0.049)$ which tends to be higher in LM group. Other clinical presentation i,e ST elevated myocardial infarction (STEMI) and chronic coronary syndrome (CCS) were comparable between the two groups with no statistically significant differences $(\mathrm{p}>0.05)$.

\section{Risk factors}

There were 9 (81.8\%) diabetic patients and 2 (18.2\%) non-diabetic patients in group 1 and $35(43.8 \%)$ patients were diabetic and $45(56.2 \%)$ were non-diabetic in group 2 . The comparative study among the two groups showed statistically significant difference $(\mathrm{p}=0.018)$. Similarly, in respect to positive family history of $\mathrm{CAD}$, there was statistically significant difference among the two groups by comparative analysis $(\mathrm{p}=0.005)$. All the other risk factor variables among the two groups showed no statistically significant differences $(\mathrm{p}>0.05)$.

\section{Biochemical tests and echocardiography}

By comparative study, there was statistically significant difference between the two groups in respect to $\mathrm{HbAlc}$ $(p=0.029)$ which tended to be higher in group 1 but no significant difference was noted in case of lipid profiles $(\mathrm{p}>0.05)$.

Majority (53\%) of the study subjects had the left ventricular ejection fraction in the range of $45-60 \%$. The comparative analyses of mean value and standard deviation of left ventricular ejection fraction (LVEF) and presence of regional wall motion abnormality (RWMA) among the study groups showed no statistically significant difference $(\mathrm{p}>0.05)$.

\section{Coronary angiography}

This study included 91 patients who underwent cardiac catheterization for coronary angiography. Among the 91 patients, there were 8 patients $(8.8 \%)$ had normal or noncritical coronary arteries, 21 patients $(23.1 \%)$ had single vessel disease, 28 patients $(30.8 \%)$ had double vessel disease and 34 patients (37.3\%) had triple vessel disease.

Regarding the frequency of left main artery affection among the studied sample, there are 80 patients $(87.92 \%)$ who have no left main artery involvement while 11 patients $(12.08 \%)$ have left main disease.

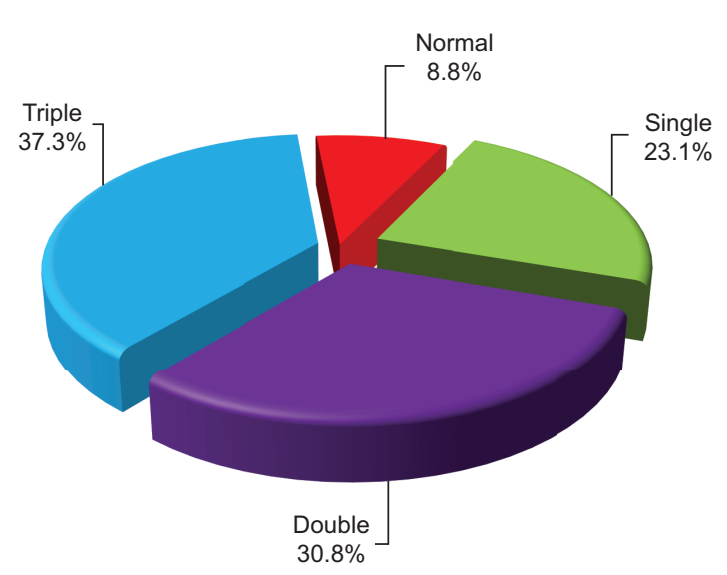

Fig.-1: Pie chart showing coronary artery involvement

In group 1, there was no isolated left main stenosis, 2 patients had single vessel disease, 3 patients had double vessel disease and 6 patients had triple vessel disease. On the other hand, in group 2 (No LMCA), 8 patients had normal coronary arteries, single vessel was affected in 19 patients, double vessel in 25 and triple vessel in 28 patients. The comparative study among the two groups revealed no statistically significant differences $(p>0.05)$. But triple vessel disease was found more commonly than single and double vessel disease.

Among the 11 patients of left main artery stenosis, 4 patients had ostio-proximal lesion and 7 patients had distal lesion. No patient was found to have isolated left main lesion and mid shaft lesion. So distal lesion was found more frequently than other types of left main stenosis.

Eleven patients had significant LMCA stenosis and constituted the study group 1 (LMCA disease). Among these patients, no one had isolated LMCA lesions, 6 had additional lesions in 3 coronary arteries, 3 had lesions in 2 vessels ( 1 LCX and RCA and 2 LAD and LCX), and 2 patients had a lesion in 1 vessel (LAD). The remaining patients comprised the group 2 (No LMCA disease). Among the patients with single vessel disease (24\%), 11 had a lesion in the LAD, 5 in the LCX and 3 in the RCA. Among the patients with double vessel disease (31\%), 8 had lesions in the RCA and LAD, 10 in the LAD and LCX, and 7 in the RCA and LCX. 28 (35\%) patients had triple vessel disease. The comparative study of specific coronary artery between the two groups shows no statistically significant differences ( $p>0.05$ ) but LAD involvement most commonly found with both groups. 


\section{Table-I}

Associations of the various demographic, clinical, biochemical and echocardiographic variables with the presence of significant Left Main Coronary Artery (LMCA) Disease ( $N=91$ )

\begin{tabular}{|c|c|c|c|}
\hline$\overline{\text { Variables }}$ & $\begin{array}{l}\text { LMCA disease } \\
\text { Group } 1 \quad(\mathrm{n}=11)\end{array}$ & $\begin{array}{c}\text { No LMCA disease } \\
\text { Group } 2(n=80) \\
\end{array}$ & $\begin{array}{c}\mathrm{P} \\
\text { Value } \\
\end{array}$ \\
\hline$\overline{\text { Age (mean } \pm \text { SD) }}$ & $55.2 \pm 9.4$ & $55.5 \pm 12.9$ & $0.948 \mathrm{~ns}$ \\
\hline \multicolumn{4}{|l|}{ Sex } \\
\hline Male (\%) & $11(100 \%)$ & $58(72.5 \%)$ & $0.046 \mathrm{~s}$ \\
\hline Female $(\%)$ & $0(0 \%)$ & $22(27.5 \%)$ & \\
\hline $\mathrm{BMI}($ mean $\pm \mathrm{SD})$ & $22.37 \pm 2.98$ & $22.94 \pm 3.45$ & $0.603 \mathrm{~ns}$ \\
\hline \multicolumn{4}{|l|}{ Clinical presentation } \\
\hline STEMI (\%) & $1(9 \%)$ & $18(23 \%)$ & \\
\hline NSTE-ACS (\%) & $8(73 \%)$ & $33(41 \%)$ & $0.049 \mathrm{~s}$ \\
\hline $\operatorname{CCS}(\%)$ & $2(18 \%)$ & $29(36 \%)$ & \\
\hline \multicolumn{4}{|l|}{ Risk factors } \\
\hline Hypertension & $9(81.8 \%)$ & $51(63.7 \%)$ & $0.236 \mathrm{~ns}$ \\
\hline Diabetes mellitus & $9(81.8 \%)$ & $35(43.8 \%)$ & $0.018 \mathrm{~s}$ \\
\hline Dyslipidemia & $5(45.5 \%)$ & $35(43.8 \%)$ & $0.915 \mathrm{~ns}$ \\
\hline Smoking & $4(36.4 \%)$ & $36(45.0 \%)$ & $0.588 \mathrm{~ns}$ \\
\hline Family history of CAD & $9(81.8 \%)$ & $30(37.5 \%)$ & $0.005 \mathrm{~s}$ \\
\hline Heart failure & $7(63.6 \%)$ & $28(35.0 \%)$ & $0.067 \mathrm{~ns}$ \\
\hline \multicolumn{4}{|l|}{ Biochemical tests } \\
\hline $\operatorname{HbAlc}(\%$, mean $\pm \mathrm{SD})$ & $8.9 \pm 1.0$ & $7.1 \pm 1.3$ & $0.029 \mathrm{~s}$ \\
\hline \multicolumn{4}{|l|}{ Lipid profiles } \\
\hline Total cholesterol & $195.9 \pm 73.9$ & $190.6 \pm 66.9$ & $0.806 \mathrm{~ns}$ \\
\hline Triglyceride & $210.0 \pm 61.0$ & $195.5 \pm 62.3$ & $0.470 \mathrm{~ns}$ \\
\hline HDL-C & $44.5 \pm 12.3$ & $46.9 \pm 9.8$ & $0.460 \mathrm{~ns}$ \\
\hline LDL-C & $120.3 \pm 36.8$ & $124.6 \pm 31.8$ & $0.677 \mathrm{~ns}$ \\
\hline EchocardiographyLVEF (mean \pm SD) & $51.5 \pm 9.1$ & $52.5 \pm 9.8$ & $0.750 \mathrm{~ns}$ \\
\hline RWMA (\%) & $4(9.3 \%)$ & $39(90.7 \%)$ & $0.440 \mathrm{~ns}$ \\
\hline
\end{tabular}

BMI=Body Mass Index, STEMI=ST Elevation Myocardial Infarction, NSTE-ACS=Non-ST Elevation-Acute Coronary Syndrome, $\mathrm{CCS}=$ Chronic Coronary Syndrome, $\mathrm{CAD}=$ Coronary Artery Disease, HDL-C=High Density Lipoprotein-Cholesterol, LDL-C=Low Density Lipoprotein-Cholesterol, LVEF=Left Ventricular Ejection Fraction, RWMA=Regional Wall motion Abnormality

\section{Table-II}

Comparison of angiographic characteristics of patients with or without left main coronary artery disease (N=91)

\begin{tabular}{|c|c|c|c|}
\hline$\overline{\text { Variables }}$ & $\begin{array}{l}\text { LMCA disease } \\
\text { Group } 1(\mathrm{n}=11)\end{array}$ & $\begin{array}{l}\text { No LMCA disease } \\
\text { Group } 2(\mathrm{n}=80)\end{array}$ & $\begin{array}{c}\mathrm{P} \\
\text { Value }\end{array}$ \\
\hline \multicolumn{4}{|l|}{ Pattern of coronary artery } \\
\hline \multicolumn{4}{|l|}{ Involvement } \\
\hline Normal/Non-critical & $0(0 \%)$ & $8(10 \%)$ & $0.294 \mathrm{~ns}$ \\
\hline Single vessel disease & $2(18 \%)$ & $19(24 \%)$ & $0.718 \mathrm{~ns}$ \\
\hline Double vessel disease & $3(27 \%)$ & $25(31 \%)$ & $0.823 \mathrm{~ns}$ \\
\hline Triple vessel disease & $6(55 \%)$ & $28(35 \%)$ & $0.320 \mathrm{~ns}$ \\
\hline \multicolumn{4}{|c|}{ Pattern of specific coronary artery involvement } \\
\hline LAD & $10(91 \%)$ & $57(71 \%)$ & $0.476 \mathrm{~ns}$ \\
\hline LCX & $9(82 \%)$ & $50(63 \%)$ & $0.455 \mathrm{~ns}$ \\
\hline RCA & $7(64 \%)$ & $46(58 \%)$ & $0.802 \mathrm{~ns}$ \\
\hline
\end{tabular}

LAD $=$ Left Anterior Descending, LCX=Left Circumflex, RCA=Right Coronary Artery, LM=Left Main Coronary Artery 


\section{Discussion}

In this study, among 91 patients of coronary artery disease, the frequency of significant left main coronary artery stenosis was $12.08 \%$, a percentage similar to $16 \%$ of LMCA involvement encountered in a recently published study6 although that study was performed only on 103 high-risk NSTE-ACS patients. Claver et al., (2006) found the frequency of significant LMCA stenosis $13.7 \%$ among 102 high-risk NSTE-ACS patients ${ }^{7}$ while Palaparthi et al., (2017) found $17 \%{ }^{8}$ both of which are consistent with the finding of this study. But Gehani et al., (2012) found $3 \%$ significant LMCA stenosis among patients who underwent coronary angiography for any reason in Iran. ${ }^{9}$ The frequency of LMCA disease reported in western countries is between $0.7 \%$ to $12.6 \%{ }^{3}$ However, the frequency of left main coronary artery disease was not so infrequent in this study compared to that of western and middle eastern countries.

The mean age for patients with LMCA stenosis was 5569 years in different studies. ${ }^{10,11}$ which was in accordance with this study. Chitman et al., (1981) in the CASS study found an association between advanced age and LMCA disease. ${ }^{5}$ Claver et al., (2006) showed advanced age as a risk factor for LMCA disease. ${ }^{7}$ But it is not true always and some studies found it equivocal. Palaparthi et al., (2017) demonstrated $89 \%$ of patients with LMCA disease are younger than 65 years. ${ }^{8}$ This study found that patients with LMCA disease were more common below the age of 65 years $(73 \%)$ but no statistically significant difference between two groups.

Male gender was considered as a risk factor for LMCA disease with more than $70 \%$ prevalence. The percentage of male patients was higher in some studies. ${ }^{12}$ In contrast to it, Claver et al., (2006) and Gehani et al., (2012) did not find any difference between the two groups. Even in one study, the percentage of male patients was lower (48\% vs. $69 \%) .{ }^{13}$ In contrast to it, this study found all the patients with left main disease were to be men with $72.5 \%$ men in non-LMCA group with statistically significant difference $(\mathrm{p}<0.05)$.

In this study, majority (64\%) of the study subjects were normal weight followed by overweight $(32 \%)$. When compared between two groups, no statistically significant difference existed $(p>0.05)$. In most studies, it was also not different between the two groups. ${ }^{14,15}$

Regarding analysis of clinical presentation of LMCA disease patients, majority (73\%) presented with NSTEACS similar to Muhammad Yousuf Shaikh et al., (2012) study who demonstrated NSTE-ACS proportion in LMCA
$71.9 \%{ }^{16}$ Similar finding was also reported by Malladi Rao et al., (2015). ${ }^{17}$ The comparative study of the clinical presentations between two groups showed statistically significant difference between the two groups in respect to NSTE-ACS $(\mathrm{p}<0.05)$ which tended to be higher in LMCA group.

When the risk factors were analyzed, the association of these risk factors with the presence of LMCA stenosis is controversial with discrepant results. Some studies found association with some risk factors while other studies found with others. This study found an association of diabetes mellitus ( $p=0.018)$ and family history of $\mathrm{CAD}(\mathrm{p}=0.005)$ with LMCA disease by comparative study. However, the prevalence of diabetes, hypertension, dyslipidemia and smoking was not different between two groups shown in some studies ${ }^{10,13,18}$ while the prevalence of diabetes, dyslipidemia and smoking was higher in LMCA group in other studies. ${ }^{7,15,19}$ Interestingly, in one study, prevalence of hypertension, dyslipidemia, and smoking in patients with LMCA disease was less common. ${ }^{9}$ Regarding hypertension in this study, there was no significant relationship between hypertension and the incidence of left main disease $(\mathrm{p}=0.236)$, similar to that found by Alshari et al., (2011). ${ }^{20}$ However, Van't Hof et al., (2008) observed that there was a significant relationship between hypertension and LMCA. ${ }^{21}$

In case of other risk factors like dyslipidemia, smoking this study did not find any statistically significant association with LMCA disease. However, Askari et al., (2019) found that the patients in LM group were more likely to be dyslipidemic and cigarette smoker. ${ }^{22}$ The prevalence of family history of CAD was $12-47 \%$ in different studies. In this study it was $43 \%$ and got a significant association with LMCA disease group. However, while it was not evaluated in several studies, the prevalence of family history of CAD was not different in the two groups in the studies by Taimur et al., (2011) and Mahajan et al., (2006).

Regarding echocardiography findings, this study found that majority of the patients with significant LMCA disease had ejection fraction of $45-60 \%$ which was in accordance with previously published literature by Askari et al., (2019). In this study, the mean left ventricular ejection fraction between two groups were comparable with no statistically significant difference $(p>0.05)$. Similar findings were also reported by Gehani et al., (2012) $(\mathrm{p}=0.93)$. This was in contrast with the finding by Claver et al., (2006) where they showed that mean Left ventricular ejection fraction of LMCA patients was less than that of non-LMCA patients 
$(p=0.044)^{7}$ although their study subjects were only NSTEACS. In case of regional wall motion abnormality (RWMA), this study did not find any significant association with the presence of LMCA stenosis. However, this finding differed from the study by Alshari et al., (2011) where the comparative analysis between the two studied groups showed statistically significant difference $(\mathrm{P}<0.05) .{ }^{20}$

Among biochemical tests, this study found significant difference in HbA1c level between two groups where HbA1c level tended to be higher in LMCA ( $p=0.029)$. But regarding lipid profiles, no significant differences between two groups were noted ( $p>0.05)$.

On analysis of coronary angiography findings, $87.92 \%$ patients had no left main artery involvement while $12.08 \%$ had left main disease. In group 1 (LMCA), there was no isolated left main stenosis, $9.5 \%$ patients had single vessel disease, $10.7 \%$ double vessel disease and $17.6 \%$ triple vessel disease. Malladi Rao et al., (2015) showed these percentages as $7.6 \%, 10.1 \%$ and $7.8 \%$, respectively. The comparative study among the two groups revealed no statistically significant differences $(\mathrm{p}>0.05)$ in respect to single, double or triple vessel disease in this study. In study by Askari et al., (2019), triple vessel disease was also not different between two groups $(\mathrm{p}=0.13)$. However, triple vessel disease was found more commonly than single and double vessel disease in this study.

Malladi Rao et al., (2015) demonstrated the different anatomical site of involvement in left main coronary artery stenosis with $17 \%$ ostio- proximal involvement, $11 \% \mathrm{mid}$ shaft disease and in majority of cases distal disease was seen $(70.3 \%)$. Among distal lesions, bifurcation type was the most common in their study. In our study, among the patients of left main coronary artery stenosis, 36\% patients had ostio-proximal lesion while $64 \%$ had distal lesion with bifurcation type was the most common among distal lesions (58\%). Similar findings were also reported in the study by Shah Ibrahim et al., (2012). So distal lesion was found more frequently than other types of left main stenosis in most studies including this study which was also corroborated by Gehani et al., (2012) revealing two thirds of cases had LM stenotic lesions in the distal part.

Regarding specific coronary artery involvement, this study revealed LAD (73.6\%) was the most commonly affected followed by LCX and RCA in both groups. Similar finding was also demonstrated by Mathew et al., (2017) who showed LAD as the most common vessel involved. ${ }^{23}$ However, the comparative study of specific coronary arteries between the two groups showed no statistically significant difference in our study $(\mathrm{p}>0.05)$.
So, this study found male sex, diabetes mellitus, positive family history of CAD and clinical presentation of NSTEACS to be significantly associated with the occurrence of LMCA disease.

\section{Conclusion}

Left main coronary artery disease contributes to an undeniable and significant proportion of patients of CAD patient population. In this study, they were relatively younger than the western left main disease cohort and showed male preponderance. They frequently presented with NSTE-ACS with multiple risk factors, of which diabetes mellitus and family history of CAD had significant association. Most patients of left main coronary artery disease revealed triple vessel disease and distal lesion was the most common anatomical site of involvement but did not show any statistically significant difference from the non-left main disease patients angiographically.

Sampling method in the study was purposive, so there was risk of selection bias. It was confined to patients who underwent coronary angiography; thus, the real prevalence of left main coronary artery disease in the general population may remain unknown. As it was a single centered study, further large-scale study is needed involving multiple centers with adequate study population to find out the exact characteristics of patients with left main coronary artery disease in Bangladesh.

\section{References}

1. Levine GN, Bates ER, Blankenship JC, Bailey SR, Bittl JA, Cercek B, Chambers CE, Ellis SG, Guyton RA, Hollenberg SM, Khot UN. 2011 ACCF/AHA/SCAI guideline for percutaneous coronary intervention: executive summary: a report of the American College of Cardiology Foundation/American Heart Association Task Force on Practice Guidelines and the Society for Cardiovascular Angiography and Interventions. Catheterization and Cardiovascular Interventions. 2012 Feb 15;79(3):453-95.

2. Lee PH, Ahn JM, Chang M, Baek S, Yoon SH, Kang SJ, Lee SW, Kim YH, Lee CW, Park SW, Park DW. Left main coronary artery disease: secular trends in patient characteristics, treatments, and outcomes. Journal of the American College of Cardiology. 2016 Sep 13;68(11):1233-46.

3. El-Menyar AA, Al Suwaidi J, Holmes Jr DR. Left main coronary artery stenosis: state-of- the-art. Current problems in cardiology. 2007 Mar 1;32(3):103-93.

4. Ramadan R, Boden WE, Kinlay S. Management of left main coronary artery disease. Journal of the American Heart Association. 2018 Mar 31;7(7):e008151.

5. Chaitman BR, Fisher LD, Bourassa MG, Davis K, Rogers WJ, Maynard C, Tyras DH, Berger RL, Judkins MP, Ringqvist I, Mock MB. Effect of coronary bypass surgery on survival patterns in subsets of patients with left main coronary artery disease: report of the Collaborative Study in Coronary Artery Surgery (CASS). The American journal of cardiology. 1981 Oct 1;48(4):765-77. 
6. Garcia S, Canoniero M, Peter A, De Marchena E, Ferreira A. Correlation of TIMI risk score with angiographic severity and extent of coronary artery disease in patients with non-STelevation acute coronary syndromes. The American journal of cardiology. 2004 Apr 1;93(7):813-16.

7. Claver E, Curós A, López-Ayerbe J, Serra J, Mauri J, FernándezNofrerias E, Rodríguez- Leor O, Bernal E, Valle V. Clinical predictors of left main coronary artery disease in high- risk patients with a first episode of non-ST- segment elevation acute coronary syndrome. Revista Española de Cardiología (English Edition). 2006 Jan 1;59(8):794-800.

8. Palaparthi S. Predictors of left main coronary artery disease in high- risk patients with ACS, first episode of Non-ST segment elevation MI in India. IOSR Journal of Dental and Medical Sciences, 2017;16(6):01-05.

9. Gehani AA, El-Menyar A, Elgendy I, Abuzaid A, Ahmed E, Haque S. Clinical presentation and cardiovascular risk profiles in patients with left main coronary artery disease in a middle eastern country. Angiology. 2013 Apr;64(3):195-99.

10. Göl MK, Özsöyler I, ${ }^{a}$ ener E, Göksel S, Sarita ${ }^{\circ} \mathrm{A}, \mathrm{Ta}^{\circ} \mathrm{dem}$ r O, Bayazit K. Is left main coronary artery stenosis a risk factor for early mortality in coronary artery surgery?. Journal of cardiac surgery. 2000;15(3):217-22.

11. Virani SS, Mendoza CE, Ferreira AC, De Marchena E. Left main coronary artery stenosis: factors predicting cardiac events in patients awaiting coronary surgery. Texas Heart Institute Journal. 2006;33(1):23.

12. Mahmood KN, Mandal SC, Talukdar SH. Surgical Treatment of Left Main Coronary Artery Disease Off-Pump CABG is a Good Option. Bangladesh Heart Journal. 2015;30(2):61-67.

13. Mahajan N, Hollander G, Malik B, Temple B, Thekkoott D, Abrol S, Schulhoff N, Ghosh J, Shani J, Lichstein E. Isolated and significantleft main coronary artery disease: demographics, hemodynamics and angiographic features. Angiology. 2006 Aug;57(4):464-77.

14. Jönsson A, Hammar N, Nordquist T, Ivert T. Left main coronary artery stenosis no longer a risk factor for early and late death after coronary artery bypass surgery - an experience covering three decades. European journal of cardio-thoracic surgery. 2006 Aug 1;30(2):311-17.
15. Veeranna V, Pradhan J, Niraj A, Fakhry H, Afonso L. Traditional cardiovascular risk factors and severity of angiographic coronary artery disease in the elderly. Preventive cardiology. 2010 Jul;13(3):135-40.

16. Shaikh MY, Ahmad M, Rasheed A, Jan DM, Ali M. Left main disease - patient profile. Pakistan Heart Journal. 2012;40(1-2).

17. Rao MS. Angiographic profile of left main coronary artery (LMCA) stenosis. Journal of Evolution of Medical and Dental Sciences. 2015 Feb 16;4(14):2376-81.

18. Taimur SD, Haq MM, Ahmed T, Karim MR, Rashid MA, Khan SR, Mansur M, Chowdhury MZ, Nasreen S, Amin MN. Risk Factors for Isolated Left Main Coronary Artery Disease. Ibrahim Cardiac Medical Journal. 2011;1(1):17-21.

19. Soleimani A, Abbasi A, Kazzazi EH, Hosseini K, Salirifar M, Darabian S, Sadeghian S, Sheikhfathol-Lahi M. Prevalence of left main coronary artery disease among patients with ischemic heart disease: insights from the Tehran Angiography Registry. Minerva cardioangiologica. 2009 Apr 1;57(2):175-83.

20. Alshari MH, Alcekelly MM,Al-Daydamony MM, Arab MA. Early, Non-Invasive Predictors of Left Main OR 3- Vessel Disease in Patients with Non-ST-Segment Elevation Acute Coronary Syndrome. Zagazig University Medical Journal. 2015 Jun 24;17(4).

21. Van't Hof AW, Ten Berg J, Heestermans T, Dill T, Funck RC, van Werkum W, Dambrink JH, Suryapranata H, van Houwelingen G, Ottervanger JP, Stella P. Prehospital initiation of tirofiban in patients with ST-elevation myocardial infarction undergoing primary angioplasty (On-TIME 2): a multicentre, double-blind, randomised controlled trial. The Lancet. 2008 Aug 16;372(9638):537-46.

22. Askari B, Mahoori A, Heidari M, Nourinejad F. Left Main Coronary Artery Disease: traditional risk factors in a study from northwest of Iran. URMIA MEDICAL JOURNAL. 2019 Jan 10;29(10):719-25.

23. Mathew D, Sajeev CG. Clinico-Angiographic Profile and Prevalence of Restenosis in Patients Undergoing Percutaneous Transluminal Coronary Angioplasty to Left Main Coronary Artery: An Observational Cohort Study. World Journal of Cardiovascular Diseases. 2017;7(11):413-22. 